\title{
SySTEM FOR CONTINUOUS CONTROL OF THE Plant Protection Product
}

\author{
BERK, P.; RAKUN, J.; VINDIS, P.; LAKOTA, M.; \\ STAJNKO, D. \& BELSAK, A.
}

Abstract: One of the key issues of crop protection products, primarily for the protection of fruit trees, is the control quantitative consumption of the plant protection product (PPP) at the application. We have therefore in the research group decided for the synthesis of the fuzzy logic system, by which we may in the future enable realization of control consumption amounts a PPP in real time. Synthesis of the whole process of control was realized with a laptop HP Compaq 6830s NA779ES, simulation software package MATLAB / Simulink R2013a and fuzzy logical tool FIS (Fuzzy Inference System). Ultrasonic measuring system was used for the acquisition reflected signals from canopy of the tree. With the help of the synthesis control consumption amounts process of PPP was found, that we can reduce the quantitative use of PPP, through the solenoid proportional control valve in the range of 0 to 100 $\%$, depending on the intensity of the reflected signal from canopy of the tree.

Key words: process, plant protection product, fuzzy logic system, measuring system, simulation
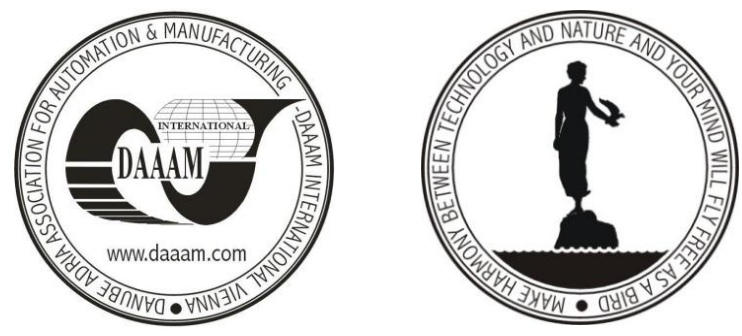

Authors' data: Msc. Berk, P[eter]*; Dr. Rakun, J[urij]*; Dr. Vindis, P[eter]*; Assoc. Prof. Lakota, M[iran $]^{*}$; Assoc. Prof. Stajnko, D[enis]*; Dr. Belsak, A[les]**, *University of Maribor, Faculty of Agriculture and Life Sciences, Pivola 10, SI-2311, Hoce, Slovenia, **University of Maribor, Faculty of Mechanical Engineering, Smetanova ulica 17, SI-2000, Maribor, Slovenia, peter.berk@um.si, rakun.jurij@um.si, peter.vindis@um.si,miran.lakota@um.si, denis.stajnko@um.si, ales.belsak@um.si

This Publication has to be referred as: Berk, P[eter]; Rakun, J[urij]; Vindis, P[eter]; Lakota, M[iran] \& Stajnko, D[enis] (2014). System for Continuous Control of the Plant Protection Product, Chapter 17 in DAAAM International Scientific Book 2014, pp.197-206, B. Katalinic (Ed.), Published by DAAAM International, ISBN 978-3-901509-98-8, ISSN 1726-9687, Vienna, Austria

DOI: $10.2507 /$ daaam.scibook.2014.17 
Berk, P.; Rakun, J.; Vindis, P.; Lakota, M. \& Stajnko, D.: System for Continuous C...

\section{Introduction}

Different types of pesticides, which include insecticides, herbicides and fungicides, we use for controlling a wide spectrum of insect pests, weeds and for controlling fungi, which cause plant disease. Due to the widespread use of pesticides in food production, people are exposed to the high content of pesticide residues in their diet, which is produced in the European Union (EU), which shows the direct dependence of agriculture on PPP. Even for the years 1996/1997 industry for the production of PPP submitted a special report which assesses that was in 1997 users sold 2.6 billion kg PPP worldwide, where costs amounted to a staggering $\$ 37$ billion. It can be however imagine the above data that the use of pesticides in the past decade in the EU has more than doubled.

Control process for dosage of PPP in the orchard represents a complex nonlinear process, which still dominate on the market at different versions of conventional hydraulic sprayers with axial, centrifugal and tangential fans, without a control dosage of PPP. This leads to excessive use of PPP, especially in younger groves orchard, where it is still based on different empirical models in EU members determine the dose of PPP. With the development of advanced ultrasonic sensor and laser measurement systems in recent years through various experiments have demonstrated, that can be measured geometric properties (leaf area, volume, height) canopy trees, which have a very large impact on the use of PPP and reduce the impact of pesticides on the environment, which may lead to drift drops of PPP (P. Balsari et al., 2008). Individual researchers have in recent years found that can reduce the use of PPP in the range of $25 \%$ to $50 \%$. In the past years have already done a lot in the field of alternative techniques of the PPP, which allow controlled dosage PPP per hectare and which will be briefly described in the following paragraph.

The first control systems for the control of quantitative doses of PPP have started to introduce (Ladd et al., 1978), (Ladd et al., 1980), in the experimental fields, where showed a reduction the use of pesticides in the range of 24 to $51 \%$, but they while achieving lower efficiency of pest management. Control systems are tested on crops of cabbage, cauliflower and peppers. In their research have demonstrated significant quantitative savings PPP by using the interrupt control methods, where using the control system to detect only the presence and absence of target objects, but not the geometrical structure of the target of the canopy structures.

At the end of the 80's (D. K. Giles et al., 1989), as made the first commercially available control system for spray application equipment in an orchard, thereby applying Ropers patent sprayer with the air support. In their research was the first to use five ultrasonic sensors for measuring distance, which are installed on each side of a vertical rod, that are installed on the spray component. The individual nozzles, which are produced exit beams, on the left and right sides of the spray components divided into five separate operated segments, where operates each segment separately, with one of the ultrasonic sensor. In the working controlled process of PPP, with the help of sensors perceived the presence and absence of leaf area in the canopy of trees in the orchard, at five different heights of the tree, where later activated individual control segments. 
In an initial approach, the authors used control solenoid valves in the ON/OFF mode. Then they started to develop a variety of hydraulic systems for the application of PPP, which consisted of three discrete state, by means of which controls the volume flow rates of PPP through the single nozzle, on both sides sprayer. Discrete states are occupied, the following values of individual variables: no flow, half flow and full flow quantification PPP, (Molto et al., 2001).

Controlling the flow rate of PPP is obtained by means of alternative application techniques, which included a system of nozzles and which are controlled by using $10 \mathrm{~Hz}$ pulse width solenoid valves on a horizontal spray set, is the solution of (Han et al., 2001), and (Pierce, 2001). Duty cycle pulse width solenoid valve is determined by using of quantitative flow variable of the PPP, while the remaining sample (drop PPP) during the application of the PPP unchanged (Giles et al., 1990). In the case where a modulated signal is $70 \%$ open, is the size of the flow through the nozzle 70 $\%$ cycle of the control signal solenoid valve, during application of PPP, $30 \%$ of the remainder of the cycle of the solenoid valve remains closed.

(Stajnko et al., 2012) in the research work describes the basic elements of a prototype automated grower sprayer, by which the selectively refer drops PPP, according to the structure of the target object, which represented the crown of the tree in the orchard. (Stajnko et al., 2012) in their work perceive the leaf canopy density of trees using ultrasonic sensors PROWAVE 400EP250, which is controlled by using the Cypress PSOC CY8C29466 microcontroller. (Stajnko et al., 2012) found that it can be with the help of programmable microcontrollers and solenoid valves reduce the quantitative use of PPP to $48.15 \%$, with the application of the PPP.

\section{Design synthesis dosage application of PPP using software and hardware components}

The classical algorithms for controlling automated applications require mathematical models for process, we want to be controlled or regulated. However, many of the physical processes is very difficult or impossible to mathematically modeling. In addition, many application processes, which have a non-linear characteristic or are simply too complex, to be able to use the classic closed-loop control method. Be aware of the need to that control quantitative dose PPP very dynamic process. Therefore, it is necessary to draw attention to changes that occur outdoors, where various forms of tree crown and barriers between lines of canopy trees can lead to wide ranges of tractor speed, pulling behind a sprayer. Therefore, in practice, more frequently use application that is the most adaptable to the current situation on the ground.

That, we can define quality process control application of PPP, at selected canopy trees, we are in the process model integrated the fuzzy logic system. Entire structure of dosage process is shown in Figure 1. Structure of the synthesis process of application PPP, we have done with the help of software tools Matlab/Simulink and hardware components. 
Berk, P.; Rakun, J.; Vindis, P.; Lakota, M. \& Stajnko, D.: System for Continuous C...

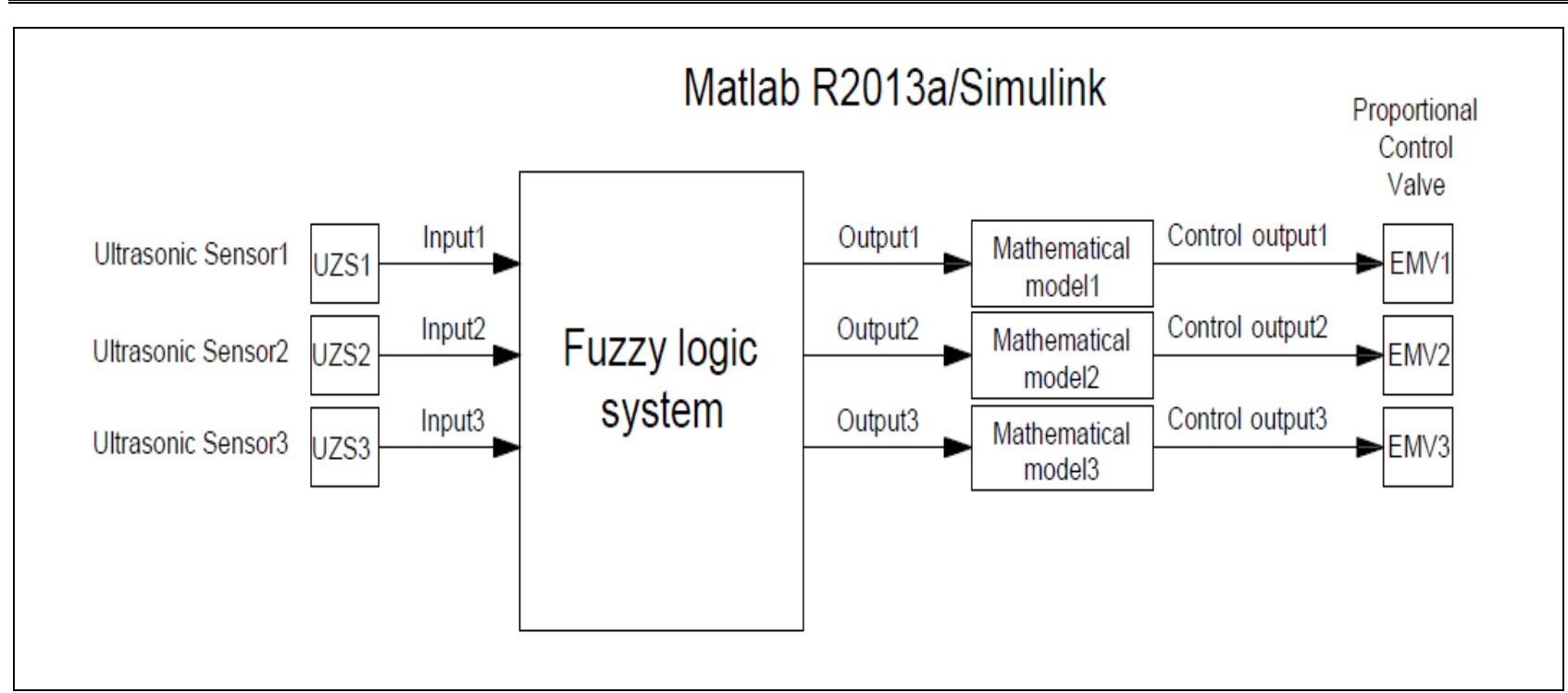

Fig. 1. Structure of synthesis dosage process of PPP

\subsection{Hardware}

The hardware of the synthesis process for the application of PPP consists of:

- A hardware control cycle consists of the HP Compaq 6830s. A HP 6830s Laptop has a 3 GB DDR2 $800 \mathrm{Mhz}$ memory, expandable to 8 GB. Hard Drive has capacity of $320 \mathrm{~GB}$, supports SMART SATA bus communicates and operates plants in 5400 in a minute and

- Posiflow Proportional Solenoid Valves, ASCO procuder, type 2/2 8202 with a flow rates adjustable between $0 \%$ and $100 \%$ of rating and flow rate can also be regulated by a range of electrical inputs (sensors, transmitters, PLC, etc.).

\subsection{Software Matlab/Simulink R2013a}

Matlab is a software package designed for numerical calculations, such as arithmetic operations of vectors, differential equations and presentation of results. For such extensive use the Matlab has available libraries through, which more knowledge about the regulation (continuous, discrete, fuzzy), designing of filters, XPC Target System can be reached. Due to the ease of use Matlab to become a tool, they have become widely used. It is suitable for teaching, research and solve practical problems. MATLAB language has rich data structures and also object-oriented. Because Matlab interprets own files, the loss of much valuable time, but it is possible to code m-files to translate and thus significantly speed up the implementation of the program. On the other hand, bottlenecks program, who spend the most time, encoded in any other programming language, such as C. Matlab code can be translated into mex-file, it know how to use Matlab as its own m file, only that translated performed much faster. Matlab has some distinctive advantages:

- quickly and easily writing programs,

- available to receive high-quality tools for visualization,

- program running on multiple operating systems and 
- special offers software tools for working with fuzzy logic systems (FIS; fuzzy inference system), which may include the acquisition and processing of data from external devices by using the tools DAQ (Data Acquisition Toolbox).

As a basic tool for the design of fuzzy logic system, we used Matlab Simulink subsystem, through which you can expand the area of nonlinear dynamical simulations, time-dependent processes. Simulink enables the development of functional units of fuzzy systems in a simple way, with the known structures of different process models and control loops. Such are created possibilities for the combination of fuzzy logic and conventional techniques and their simulation testing. The simple and open system architecture Matlab program it is possible to realize all the usual procedures and a Simulink tool also offers the possibility of optional finishing and extension.

\subsection{Fuzzy logic tool FIS}

Three partial processes of fuzzy logical system we planned with the help of fuzzy logical tools FIS, which is implemented in the Matlab program. For the construction, editing, and monitoring fuzzy logic system, exists in the FIS five basic components. These are:

- editor for the determination of fuzzy inference system FIS ("FIS Editor"),

- membership function editor,

- rule editor,

- rule viewer and

- surface viewer.

In the system of the FIS are dynamically integrates and interconnected all core components. Any changes that have an impact on individual functional components, such as various settings membership functions of input and output variable, can be set in the fuzzy logic system FIS. In the FIS, we set a different number of inputs and output variables for our fuzzy logic system, with which was continuously controlled the synthesis process of application of PPP. In the editor membership functions was identify their triangular, trapezoidal and rectangular shape. Editor of the rules we used to edit the list of rules, through which was determined the response of fuzzy logic system. Rule viewer represent Matlab technical tool, that shows fuzzy diagrams of membership functions in the field of operating point. The rule viewer is used for the diagnosis of active rules and provides, how different forms of membership functions repercussions on the final calculation of the output value linguistic variable of fuzzy logic system. With the help of the surface viewer the characteristic fields can show the output values of the variables of the fuzzy system, which depend on different sets of input values of the variables of the fuzzy system.

\section{Process model application of PPP with fuzzy logical system}

Fuzzy logic system for continuous control of the proportional solenoid valve, which was made by using Simulink subsystem, Matlab R2013a and software tools 
Berk, P.; Rakun, J.; Vindis, P.; Lakota, M. \& Stajnko, D.: System for Continuous C...

FIS, can be considered as a system with non-linear static characteristic in the application process of PPP. Therefore, we are in the process of application of PPP include fuzzy logic system, where form of non-linearity of the fuzzy logic system depends on the rule base and membership functions of input and output linguistic variables depends on the rule base and membership functions of input and output linguistic variables tagged with: Sensor1, Sensor2, Sensor3, El-mag-V1, El-mag-V2 and El-mag-V3. Optimization of fuzzy system, we started with the process of fuzzification three input and three output linguistic variables. Input and output linguistic variable fuzzy system, we are defined each of them with a reference value in the interval $[0,600]$. Reference values for each input linguistic variables of the system represented the normalized intensity values reflection of the ultrasound signal from the tree canopy, which was captured via the ultrasonic sensor (Berk et al., 2013). Reference values for each output linguistic variables of the fuzzy system represented the values, with which we can continuously controlled solenoid valves on the sprayer, in the range from $0 \%$ to $100 \%$. Input and output linguistic variables was by using tools FIS, described by three membership functions trapezoidal shape, shown in Figures 2 and 3, whereas, in this case trapezoidal membership functions shown as the most suitable. Membership function was presented with linguistic values described in Table 1.

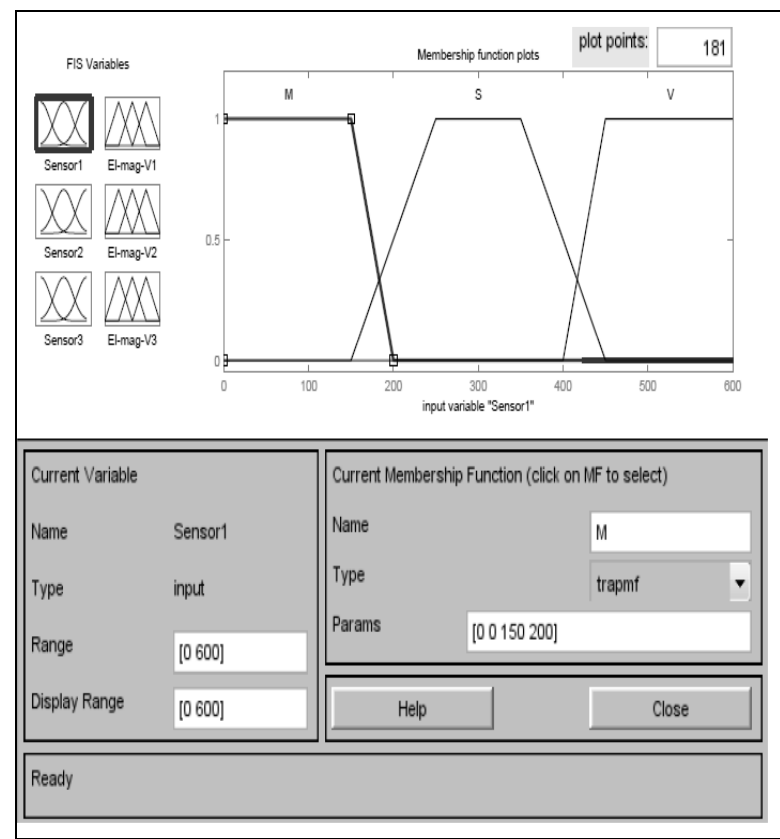

Fig. 2. Membership functions of linguistic variables: Sensor1, Sensor2 in Sensor3
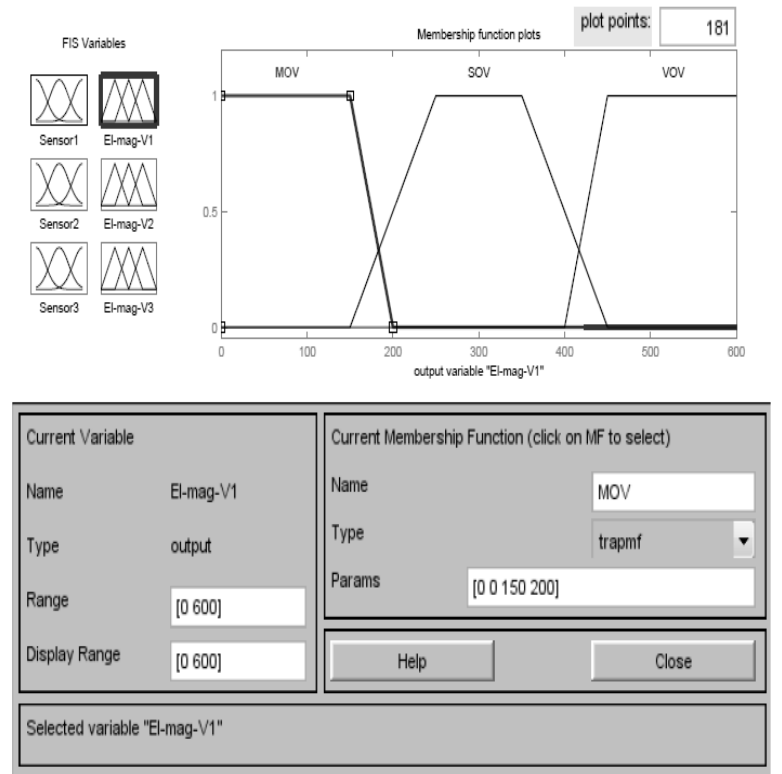

Fig. 3. Membership functions of linguistic variables: El-mag-V1, El-mag-V2, El-mag-V3

\begin{tabular}{|c|c|}
\hline Linguistic value* ${ }^{*}$ (label in the FIS) & $\begin{array}{c}\text { The rate of linguistic values } \\
\text { (describe in words) }\end{array}$ \\
\hline M & Low \\
\hline S & Middle \\
\hline V & Lot \\
\hline MOV & A little open valve \\
\hline SOV & Medium open valve \\
\hline VOV & Lots of open valve \\
\hline
\end{tabular}


*The rate of linguistic values ranged between 0 and 1

Tab. 1. Description of the degree of linguistic value membership functions of fuzzy logic system

After completing the process of fuzzification three input and three output linguistic variables was continue with the procedure inference, which represents the decision-making process. The procedure was carried out, that we wrote a multitude of rules in the form of Table 2, for the control of the proportional solenoid valve 1 . The total number $\mathrm{N}$ of possible rules for the fuzzy logic system was defined by the formula:

$$
\mathrm{N}=\mathrm{p}^{\mathrm{m}}=3^{3}=27
$$

Whereby:

$\mathrm{p}$ - number of levels linguistic values for each input linguistic variable and $\mathrm{m}$ - number of input linguistic variables.

\begin{tabular}{|c|c|c|c|c|}
\hline \multicolumn{5}{|c|}{ The rules for controlling solenoid valve 1 } \\
\hline Rule & Input (Senzor 1) & Input (Senzor 2) & Input (Senzor 3) & $\begin{array}{c}\text { Output } \\
\text { (El-mag-V1) }\end{array}$ \\
\hline 1 & M & M & M & MOV \\
\hline 2 & S & S & S & SOV \\
\hline 3 & V & V & V & VOV \\
\hline 4 & M & M & S & MOV \\
\hline 5 & M & M & V & MOV \\
\hline 6 & M & S & M & MOV \\
\hline 7 & M & S & S & MOV \\
\hline 8 & M & S & V & MOV \\
\hline 9 & M & V & M & SOV \\
\hline 10 & M & V & S & SOV \\
\hline 11 & M & V & V & SOV \\
\hline 12 & S & M & M & SOV \\
\hline 13 & S & M & S & SOV \\
\hline 14 & S & M & V & SOV \\
\hline 15 & S & S & M & SOV \\
\hline 16 & S & S & V & SOV \\
\hline 17 & S & V & M & SOV \\
\hline 18 & S & V & S & SOV \\
\hline 19 & S & V & V & SOV \\
\hline 20 & V & M & M & VOV \\
\hline 21 & V & M & S & VOV \\
\hline 22 & V & M & V & VOV \\
\hline 23 & V & S & M & VOV \\
\hline 24 & V & S & S & VOV \\
\hline 25 & V & S & V & VOV \\
\hline 26 & V & V & M & VOV \\
\hline 27 & V & V & S & VOV \\
\hline
\end{tabular}

Tab. 2. Rules for controlling electromagnetic valve 1 for the process of application of PPP 
Importance of levels membership functions of each linguistic variable shows Table 1. Language description of the fuzzy logic system, we have made with the form "IF THEN" and the total number of rules is 27 . The rules was added to the rules editor in the fuzzy logical tools FIS.

In the language of control techniques we have assumed: if the input value of the ultrasound sensor, (Berk et al., 2013), 1, 2 and 3 is small, then the solenoid valves a little open, depending on the working area of a proportional solenoid valve. After the establishment of rules for controlling the solenoid valves we have created inference, which represented the set of fuzzy output, using the operator inference. In the fuzzy logic system was used Mamdani operator inference, with whom we have created a set of all membership functions of the rules, relating to the output parameter. Then followed a procedure focus, where we have chosen gravity method, which, in practice, the most frequently used and contribute best results. The method allows the calculation of the sharp in control technology useful variables, by which can be controlled executive actuators, such as proportional solenoid valves. Optimization of fuzzy logic system was carried out, that we are taking configure stability, robustness, quality of the system and behavior change in the value of the linguistic membership functions and their forms and rules. Then, we have included the design of fuzzy logic system into the final mathematical model. In the mathematical model of the system we have take into account its dynamic properties.

With the use of the subsystem Simulink we have compiled a synthesis model of fuzzy logic system by showing in Figure 4. In a system planning we have take advantage of simulation tools such as Matlab and its associated subsystems.

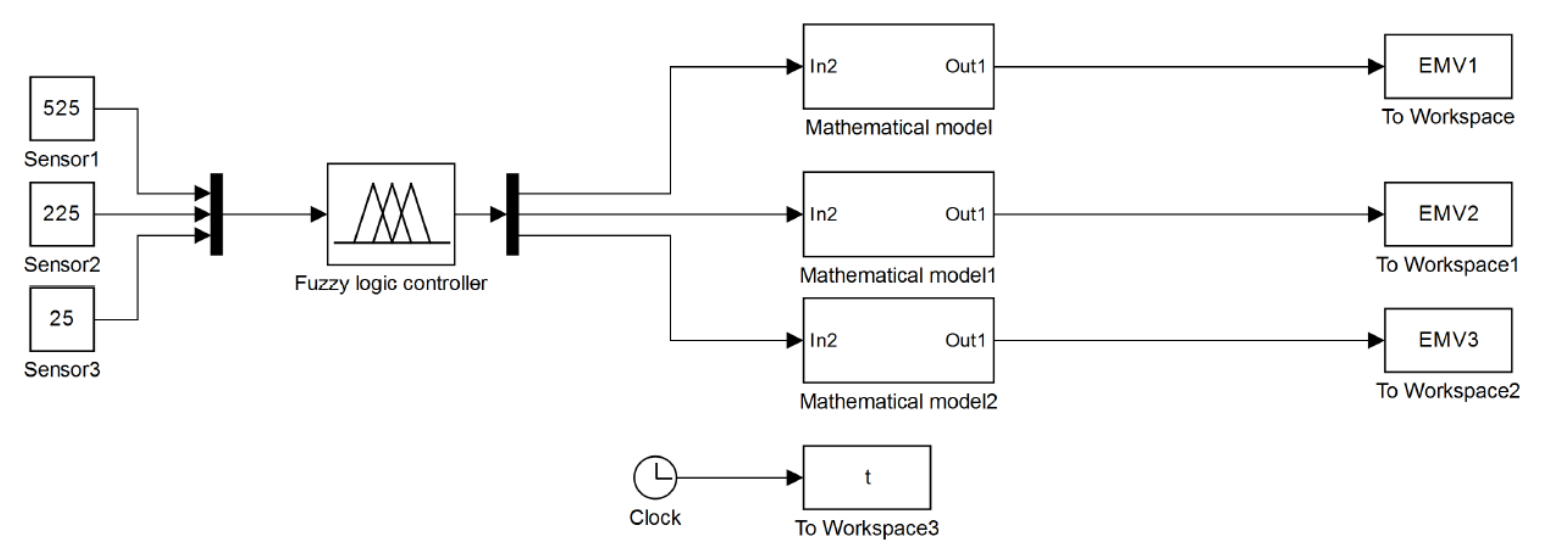

Fig. 4. Synthesis of fuzzy logic system design for the dosage process of PPP

\section{Results}

Figure 5 shows the different types of ramp output signals with which can continuously controlled proportional solenoid valves in the range of $0 \%$ to $100 \%$. The figure clearly show that in the case of large numerical values, which represented the intensity of the reflected signal from the tree canopy and which bring in first input 
of the fuzzy logic system is obtained at the first output of the fuzzy logic system openness proportional solenoid valve in the range of $85.09 \%$. In the case of smaller numerical values to the second input fuzzy logic system, is obtained at the second output of fuzzy logic system the openness of the proportional solenoid valve in the range $50.00 \%$ and a third output of $46.15 \%$ open proportional solenoid valve. The reason for $46,15 \%$ open solenoid valve on quite a bit numeric value, which bring in third input fuzzy logic system, we see in that, that impact on third output of fuzzy logical system written active rules, which are active for the first and second output fuzzy logic system.

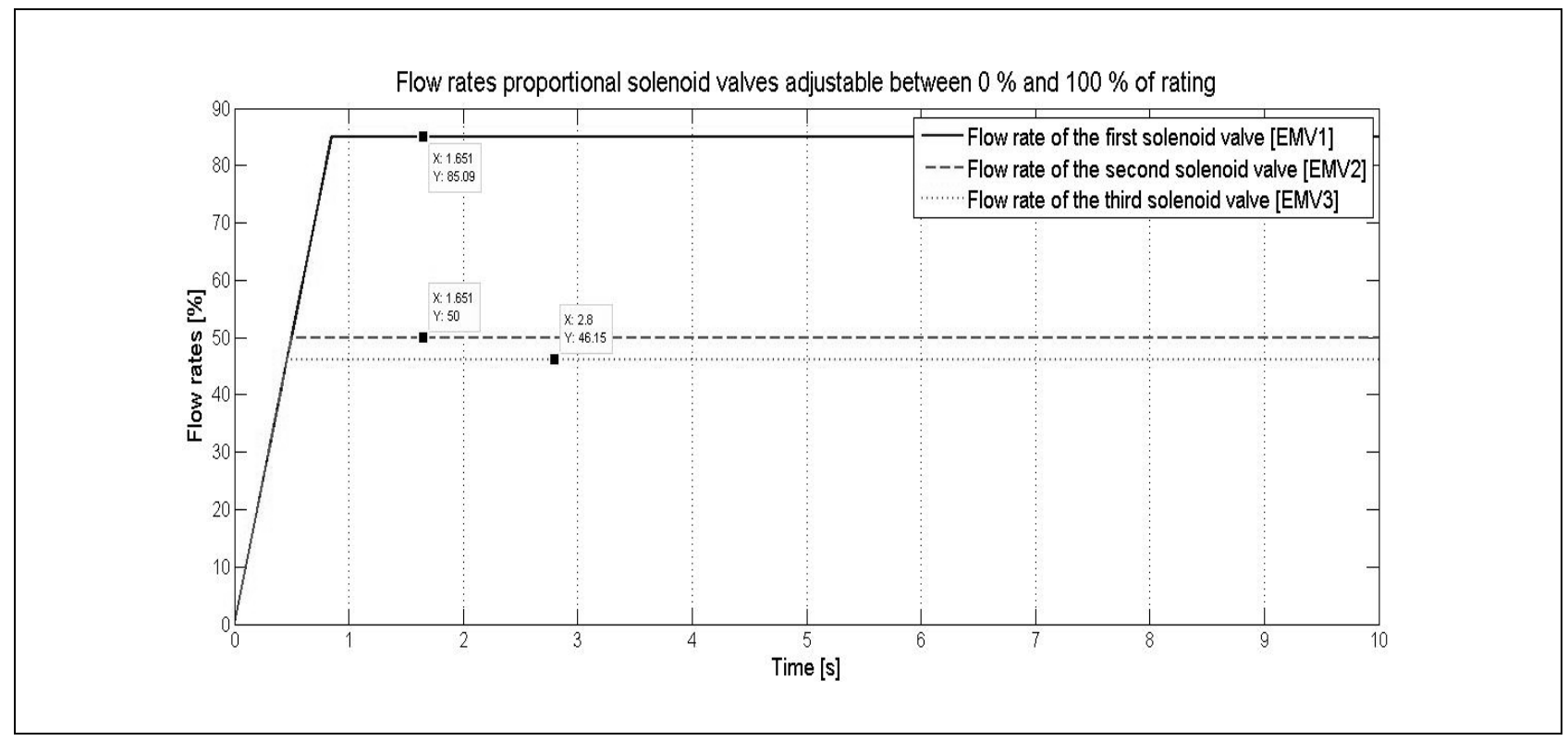

Fig. 5. Flow rates proportional solenoid valves

\section{Conclusions}

The research results confirm that could be used synthesis model of fuzzy logic system in real process of automated application of PPP in selected parts of the tree canopy, where the method of constant-direct application usually does not produce satisfactory results. We found that the fuzzy logic system allows the user to use own knowledge of the problem and transferred to the appropriate system environment, which is close to the human way of thinking. Since this is a more complex task than simply inserting control parameters, we used the special user interface (FIS) for planning fuzzy logic applications. Fuzzy logic system in the application control process of the proportional solenoid valve proved to be a very good choice, because the process of planning a fuzzy logic system is quite simple and appropriate for engineering practice.

So far, we have made the simulation of synthesis process of volume application plant protection product implemented with a fuzzy logic system. In the future we want to do real design control process which will be supported by the control and actuator units and real measurement system, where we capture real time process data, that we could control real time process for the application of PPP. 
Berk, P.; Rakun, J.; Vindis, P.; Lakota, M. \& Stajnko, D.: System for Continuous C...

\section{References}

*** (2014a) http://courses.washington.edu/css457/matlab/learning_matlab.pdf - The Mathworks, Learning Matlab, version 6, (2001), Accesed on: 2014-08-27

*** http://www.mathworks.com/help/pdf_doc/fuzzy/fuzzy - Fuzzy Logic Toolbox (2010), Accesed on: 2014-08-21

*** (2014b) http://www.ni.com/pdf/manuals/372192d.pdf - National Instruments, PID and Fuzzy Logic Toolkit User Manual (2009), Accesed on: 2014-08-28

Balsari, P.; Doruchowski, G.; Marucco, P.; Tamagnone, M., Van de Zande, J. \& Wenneker, M. (2008). 'A System for Adjusting the Spray Application to the Target Characteristics", Agricultural Engineering International, the CIGR Ejournal, 08002 Vol. X. May

Berk, P.; Rakun, J.; Lakota, M. \& Muskinja, N. (2013). DAAAM International scientific book 2013, V: Katalinić, Branko, Tekic, Zeljko, The influence of distance ultrasonic density measurements, ISSN 1726-9687, Vienna: DAAAM International Publishing, pp. 637-646

Giles, D.K.; Delwiche, M.J. \& Dodd, R.B. (1989). Sprayer Control by Sensing Orchard Crop Characteristics: Orchard Architecture and Spray Liquid Savings, $J$. Agric. Eng. Res., vol. 43, pp. $271-289$

Giles, D.K. \& Comino, J.A. (1990). Droplet size and spray pattern characteristics of an electronic flow controller for spray nozzles, J. Agric. Res., vol. 47, pp. $249-267$ Giles, K. (2009). Variable Rate Spray Application without a Change in Droplet Size, Australian Grain, vol. 18, 6, pp. 38-39

Han, S.; Hendrickson, L. L.; Ni, B. \& Zhang, Q. (2001). Modification and testing of a commercial sprayer with PWM solenoids for precision spraying, Appl. Eng. Agric., vol. 17, no. 5, pp. 591-594

Ladd, T.L. \& Reichard, D.L. (1988). Photoelectrically-operated intermittent sprayers for insecticidal control of horticultural pests, Journal of Economic Entomology, vol. 73, pp. $525-528$

Ladd, T.L.; Reichard, D.L.; Collins, D.L. \& Buriff, C.R. (1978). An automatic intermittent sprayer: a new approach to the insecticidial control of horticultural pests, Journal of Economic Entomology, vol. 71, pp. 789 - 792

Molto, E.; Martin, B. \& Gutierrez, A. (2001). Pesticide loss reduction by automatic adaptation of spraying on globular trees, J. Agric. Eng. Res., vol. 78, pp. $35-41$

Pierce, R. A. (2001). Evaluation of deposition and application accuracy of a pulse width modulation variable rate field sprayer, ASAE Paper no. 01-1077, St. Joseph, MI: ASABE

Stajnko, D.; Berk P.; Lešnik M.; Jejčič V.; Lakota M.; Štrancar A.; Hočevar M. \& Rakun J. Programmable ultrasonic sensing system for targeted spraying in orchards, Sensors, vol. 12, 11, pp. 15500-15519 